\title{
Treatment beyond four cycles of first line Platinum and Etoposide chemotherapy in real-life patients with stage IV Small Cell Lung Cancer: a retrospective study of the Merseyside and Cheshire Cancer network
}

\author{
Mostafa Sallam ${ }^{1,2}$, Helen Wong ${ }^{1}$ and Carles Escriu ${ }^{1,2^{*}}$ (1)
}

\begin{abstract}
Background: Dose intensity and dose density of first line Platinum and Etoposide (PE) do not influence Overall Survival (OS) of Small Cell Lung Cancer (SCLC) patients. The effect of treatment length, however, remains unclear. Current guidelines recommend treating beyond 4 cycles -up to 6-, in patients that respond to and tolerate systemic treatment. This has led to variable practice both in clinical practice and clinical research. Here we aimed at quantifying the possible clinical benefit of the extended regimen in our real-life patients treated with PE doublet.

Methods: Of all patients with SCLC treated in our network with non-concurrent first line PE chemotherapy between 2008 and 2015, we identified and described patients that received 4 cycles (4c) or more (> 4c), and analysed patients with stage IV disease.

Results: Two hundred forty-one patients with stage IV had 4c and 69 had $>4 c$. The latter were more likely to have sequential thoracic radiotherapy, which suggested a lower metastatic burden. Nevertheless, there were no statistically significant differences when comparing clinical outcomes. The median Duration of Response (DoR; time from last chemotherapy cycle to progression) was 5 months in both groups (HR 1.22; 95\% Cl 0.93-1.61). Median Progression Free Survival (PFS; time from diagnosis to radiological progression) was 8 months (4c) versus 9 months (> 4c) (HR 0.86; 95\% Cl 0.66-1.13) and median OS was 11 versus 12 months (HR 0.86, 95\% Cl 0.66-1.14).
\end{abstract}

Conclusion: Our results highlight a lack of clinical benefit by extending first line PE treatment in stage IV disease, and support limiting treatment to 4 cycles until superiority of a longer regimen is identified in a randomised study.

Keywords: Lung neoplasm, Small cell lung carcinoma, Drug therapy, Observational study, Antineoplastic combined chemotherapy protocols

\section{Background}

Small Cell Lung Cancer (SCLC) is the most common neuroendocrine tumour of the lung [1] and accounts for 10\% of all lung cancers [2]. Its incidence is associated with smoking, almost two thirds of patients present with advanced disease [3], and although response rates to chemotherapy are high, the benefit is short-lived. With platinum and etoposide (PE)

\footnotetext{
* Correspondence: carles.escriu@nhs.net

${ }^{1}$ The Clatterbridge Cancer Centre, Clatterbridge Road, Bebington, Wirral CH63 4JY, UK

${ }^{2}$ University of Liverpool, L69 3BX, Liverpool, UK
}

chemotherapy combination in extensive disease the median progression-free survival (PFS) is only 5.5 months and the median overall survival (OS) under 10 months [4]. These figures underline the need to optimise oncological treatment in SCLC, so that survival benefit is maximised whilst unnecessary treatment and toxicity are avoided.

When SCLC is not amenable to concurrent chemoradiotherapy, international guidelines advice 4 to 6 cycles of first line systemic Platinum (Cisplatin or Carboplatin) and Etoposide combination (PE) [5, 6]. Prophylactic Cranial Irradiation (PCI) [7], and sequential thoracic

(c) The Author(s). 2019 Open Access This article is distributed under the terms of the Creative Commons Attribution 4.0 International License (http://creativecommons.org/licenses/by/4.0/), which permits unrestricted use, distribution, and reproduction in any medium, provided you give appropriate credit to the original author(s) and the source, provide a link to the Creative Commons license, and indicate if changes were made. The Creative Commons Public Domain Dedication waiver (http://creativecommons.org/publicdomain/zero/1.0/) applies to the data made available in this article, unless otherwise stated. 
radiotherapy may be considered in patients with either limited $[8,9]$ or extensive disease [10].

So far, in SCLC more chemotherapy does not translate in more clinical benefit. Strategies increasing chemotherapy dose intensity, dose density, peak dose or total dose regimens have been studied extensively and failed to provide a survival advantage [11]. Randomised clinical trials differ in identifying a survival benefit with maintenance Topotecan or Etoposide after 4 cycles of platinum combination $[12,13]$. Two meta-analysis $[14,15]$ concur with a potential impact in PFS in extensive disease but differ in its survival benefit. Although maintenance treatment may be common practice in some countries [14] international guidelines discourage its use $[5,6]$.

The length of first line PE treatment, however, remains controversial. In the early 80's, 6 cycles of Vincristine, Doxorubicin and Cyclophosphamide (CAV) were the standard of care. A decade later Roth et al. [16] run a randomized phase III study with over 437 eligible patients. They compared 4 cycles of Cisplatin and Etoposide with 6 cycles of CAV and 6 cycles of a hybrid regimen of CAV and Cisplatinum-Etoposide. No PFS or survival differences were identified, but a higher rate of infection was found in CAV containing regimens. The only study that compared 4 versus 6 cycles of Cisplatin and Etoposide chemotherapy was published a few years later by Veslemes et al. [17]. Sixty-nine of the 70 randomised patients were analysded, and only 46 had extensive disease. The primary objective of the study was undisclosed, and there was no pre-planned subgroup analysis. Anyhow, no significant survival differences were identified other than a trend to survival gain in patients with extensive disease at the expense of higher toxicity. Chasing this possible benefit with a longer regimen appeared less intricate when outpatient Carboplatin containing doublet administration showed similar clinical benefit than the then inpatient Cisplatin based treatment $[18,19]$.

International guidelines [5, 6] continue to encourage the use of a range of chemotherapy cycle numbers. Nonetheless, this promotes variability in real-life practice and clinical research. For example, some randomised studies may use 4 cycles as standard of care control [12, 13], while others may design their study to optimise the delivery of 6 cycles [20].

Perhaps due to the limited evidence available, the optimal length of first line platinum combination treatment in recent reviews is either omitted [21-23] or maintenance treatment is discussed instead [24]. The drastically inferior benefit of second line options [5, 24] and the low impact of novel biological approaches so far [23] are factors that may influence treatment attitudes towards the length of this first line setting. This is unlikely to change in spite of the recent introduction of first-line immune therapy combination with 4 cycles of chemotherapy [25]: as long as the backbone of cytotoxic chemotherapy remains, the possibility of extending cytotoxic chemotherapy to 6 cycles will remain unchanged for as long as the perception of benefit remains unchallenged. Furthermore, extending PE chemotherapy in patients that are not amenable to first-line immune therapy combination may be the only option to attempt to optimise their survival benefit. In this context a prospective study is unlikely to materialize, and retrospective analysis of real-life patients is the only method available to identify the optimal treatment length.

The Merseyside and Cheshire Cancer Network serves a population of 2.3 million with non-surgical oncology provision and receives over 1000 new lung cancer referrals per year. Of those that receive treatment in our centre, audit data is recorded prospectively. Practice amongst oncologists is diverse and some advocate for treatment continuation beyond 4 cycles in selected patients. Here we aim at characterising that subpopulation and quantifying the possible survival gain over a four-cycle regimen.

\section{Methods}

This was a retrospective observational study of the Merseyside and Cheshire Cancer Network. Audit approval was obtained ahead of data collection according to local policy. Patients referred with pathologically confirmed small cell lung cancer and treated with Platinum and Etoposide combination regimens over an 8-year period (2008-2015) were identified. The first date was chosen to optimise prospective data record consistency, and the latter to allow mature one-year survival data. Two thousand fifteen also preceded the use of standard consolidation radiotherapy in extensive disease [10]. Patients treated with concurrent chemo-radiotherapy, non-platinum-based combination or single agent platinum, were excluded.

Epidemiological, pathological, treatment and survival data were extracted from the prospective database and confirmed retrospectively. Radiological response and progression was collected retrospectively. Lung radiotherapy was defined as radiotherapy administered to the primary lung tumour any time after systemic chemotherapy regardless of intent. Analysis on treatment outcomes were performed for stage IV SCLC ( $n=69$ for $>4 \mathrm{c}$ and $n=241$ for 4c). Progression was defined as the date of radiological progression. Duration of Response (DoR) was defined as the time from the date of administration of the last cycle of chemotherapy to the date of progression or death. Progression Free Survival (PFS) was defined as the time from diagnosis to progression or death. Overall Survival 
(OS) was defined as time from diagnosis to death or last patient review.

Chi-square contingency analysis was performed to identify epidemiological or treatment variables. PFS and OS curves were constructed using the KaplanMeier method, and compared for significance using the log-rank test. A cox proportional hazards model was used to generate univariate hazard ratios (HR) and $95 \%$ confidence intervals. A two-sided $p<0.05$ was considered as statistically significant. All statistical analyses were carried out using the statistics software IBM SPSS v.24.0 (SPSS Inc.).

This paper was written according to the STROBE criteria version 4 .

\section{Results}

\section{Patient characteristics}

Of the 671 patients that received systemic PE combination treatment without concurrent radiotherapy, 93 were selected to have more a longer regimen, of which
$24(26 \%)$ had an initial stage of I-III -half of them $(n=$ $12,13 \%)$ with limited disease-, and 69 (74\%) had stage IV disease. When comparing patients that had 4 cycles (4c) $(n=578)$ versus those that went on to have more than $4(>4 c)(n=93)$, significant differences were identified in their co-morbidity, stage and disease extent (see Table 1) as well as the proportion of second line chemotherapy received (see Table 2), but there were no differences in their best response rates to treatment. Patients selected to have a longer treatment had less comorbidity, more advanced stage and were eventually less likely to receive second line chemotherapy. These differences were not apparent when comparing patients that presented with stage IV disease, of which 241 completed 4 cycles and 69 completed more than 4 . Hence, we decided to focus in these more homogeneous subpopulation of patients with stage IV disease for outcome analysis (see Fig. 1).

In patients with stage IV both treatment groups had a similar sex distribution and an average age of 65; around

Table 1 Demographic characteristics. Percentage relative to the total at the top row is presented in brackets. Chi-square contingency analysis was performed where indicated. Statistically significant results are highlighted in italic and an asterisk

\begin{tabular}{|c|c|c|c|c|c|c|c|c|c|}
\hline & \multicolumn{3}{|l|}{ All patients } & \multicolumn{3}{|c|}{ Extensive Disease } & \multicolumn{3}{|l|}{ Stage IV } \\
\hline & $>4$ cycles & 4 cycles & $\overline{p \text { value }}$ & $>4$ cycles & 4 cycles & $\overline{p \text { value }}$ & $>4$ cycles & 4 cycles & $p$ value \\
\hline Total N & 93 & 578 & & 81 & 402 & & 69 & 241 & \\
\hline Sex, n (\%) & & & 0.115 & & & 0.113 & & & 0.218 \\
\hline Male & $48(51.6)$ & $246(42.6)$ & & $43(53.1)$ & $174(43.3)$ & & 37 (53.6) & $107(44.4)$ & \\
\hline Female & $45(48.4)$ & $332(57.4)$ & & $38(46.9)$ & $228(56.7)$ & & $32(46.4)$ & $134(55.6)$ & \\
\hline Age, Avg [Min-Max] & 65 [39-81] & 66 [37-88] & 0.847 & 65 [39-80] & 66 [37-88] & 0.358 & 65 [39-80] & 65 [41-87] & 0.812 \\
\hline PS, n (\%) & & & 0.426 & & & 0.367 & & & 0.192 \\
\hline PSO & $14(15.1)$ & $64(11.1)$ & & $14(17.3)$ & $45(11.2)$ & & $14(20.3)$ & $29(12)$ & \\
\hline PS1 & $41(44.1)$ & $288(49.8)$ & & $33(40.7)$ & $189(47)$ & & $26(37.7)$ & $122(50.6)$ & \\
\hline PS2 & $34(36.6)$ & $205(35.5)$ & & $30(37)$ & $149(37.1)$ & & $25(36.2)$ & $83(34.4)$ & \\
\hline PS3 & $3(3.2)$ & $20(3.5)$ & & $3(3.7)$ & $18(4.5)$ & & $3(4.3)$ & $6(2.5)$ & \\
\hline PS4 & $1(1.1 \%)$ & $1(0.2 \%)$ & & $1(1.2 \%)$ & $1(0.2 \%)$ & & $1(1.4 \%)$ & $1(0.4 \%)$ & \\
\hline Comorbidities, n (\%) & & & $0.01 *$ & & & $0.017^{*}$ & & & 0.140 \\
\hline None & $26(28)$ & $85(14.7)$ & & $21(25.9)$ & $60(14.9)$ & & $17(24.6)$ & $37(15.4)$ & \\
\hline Mild & $40(43)$ & $320(55.4)$ & & $35(43.2)$ & $222(55.2)$ & & $33(47.8)$ & $134(55.6)$ & \\
\hline Moderate & $24(25.8)$ & $162(28)$ & & $23(28.4)$ & $111(27.6)$ & & $17(24.6)$ & $66(27.4)$ & \\
\hline Severe & $3(3.3)$ & $11(1.9)$ & & $2(2.4)$ & $9(2.2)$ & & $2(2.8)$ & $4(1.7)$ & \\
\hline Stage, n (\%) & & & $<0.001^{*}$ & & & $<0.001^{*}$ & & & \\
\hline Stage I & $1(1.1)$ & $11(1.9)$ & & - & - & & - & - & - \\
\hline Stage II-III & $23(24.7)$ & $326(56.4)$ & & $12(14.8)$ & $161(40)$ & & - & - & \\
\hline Stage IV & $69(74.2)$ & $241(41.7)$ & & $69(85.2)$ & $241(60)$ & & $69(100)$ & $241(100)$ & \\
\hline Disease extent, n (\%) & & & $<0.001^{*}$ & & & & & & \\
\hline Limited & $12(12.9)$ & $176(30.4)$ & & - & - & & - & - & \\
\hline Extensive & $81(87.1)$ & 402 (69.6) & & $81(100)$ & $402(100)$ & & $69(100)$ & $241(100)$ & \\
\hline SVCO at presentation & $4(4.3)$ & $36(6.2)$ & 0.466 & $4(4.9)$ & $30(7.5)$ & 0.633 & $2(2.9)$ & $14(5.8)$ & 0.538 \\
\hline
\end{tabular}


Table 2 Treatment characteristics. Percentage relative to the total at the top row are presented in brackets. Chi-square contingency analysis was performed where indicated. Statistically significant results are highlighted in italic and an asterisk

\begin{tabular}{|c|c|c|c|c|c|c|c|c|c|}
\hline & \multicolumn{3}{|c|}{ All patients } & \multicolumn{3}{|c|}{ Extensive Disease } & \multicolumn{3}{|l|}{$\underline{\text { Stage IV }}$} \\
\hline & $>4$ cycles & 4 cycles & $p$ value & $>4$ cycles & 4 cycles & $p$ value & $>4$ cycles & 4 cycles & $p$ value \\
\hline Total N & 93 & 578 & & 81 & 402 & & 69 & 241 & \\
\hline 1st Line Chemotherapy, n (\%) & & & 0.148 & & & 0.557 & & & 0.689 \\
\hline Cisplatin Etoposide & $2(2.2)$ & $37(6.4)$ & & $2(2.5)$ & $20(5)$ & & $1(1.4)$ & $8(3.3)$ & \\
\hline Carboplatin Etoposide & $91(97.8)$ & $541(93.6)$ & & $79(97.5)$ & $382(95)$ & & 68 (98.6) & $233(96.7)$ & \\
\hline \multicolumn{10}{|l|}{ Cycle Number, n (\%) } \\
\hline 4 cycles & - & $578(100)$ & & - & $402(100)$ & & - & $241(100)$ & \\
\hline 5 cycles & $13(14)$ & - & & $13(16)$ & - & & $11(15.9)$ & - & \\
\hline 6 cycles & $80(86)$ & - & & $68(84)$ & - & & $58(84.1)$ & - & \\
\hline Average Cycles & 5.9 & 4 & & 5.8 & 4 & & 5.8 & 4 & \\
\hline Response, n (\%) & & & 0.461 & & & 0.9807 & & & 0.538 \\
\hline Progression & $3(3.2)$ & $13(2.2)$ & & $3(3.7)$ & $12(3)$ & & $2(2.9)$ & $8(3.3)$ & \\
\hline Stable Disease & $12(12.9)$ & $53(9.2)$ & & $11(13.6)$ & $37(9.2)$ & & $10(14.5)$ & $25(10.4)$ & \\
\hline Partial Response & $57(61.3)$ & $412(71.3)$ & & $51(63)$ & $288(71.6)$ & & $44(63.8)$ & $74(72.2)$ & \\
\hline Complete Response & $21(22.6)$ & $100(17.3)$ & & $16(18.9)$ & $62(15.4)$ & & $13(18.8)$ & $34(14.1)$ & \\
\hline Radiotherapy to lung, n (\%) & $43(46.2)$ & $254(43.9)$ & 0.736 & $35(43.2)$ & $146(36.3)$ & 0.259 & $27(39.1)$ & $61(25.3)$ & $0.033^{*}$ \\
\hline $\mathrm{PCl}, \mathrm{n}(\%)$ & $37(39.8)$ & $240(41.5)$ & 0.821 & $29(35.8)$ & $156(38.8)$ & 0.707 & $24(34.8)$ & $96(39.8)$ & 0.486 \\
\hline 2nd line Chemotherapy, n (\%) & $17(18.3)$ & $167(28.9)$ & $0.034^{*}$ & $17(21)$ & $108(26.9)$ & 0.271 & $16(23.2)$ & $62(25.7)$ & 0.754 \\
\hline CarboEtop & $7(7.5)$ & $88(15.2)$ & 0.804 & $7(8.6)$ & $47(11.7)$ & 0.796 & $6(8.7)$ & $29(12)$ & 1.000 \\
\hline Topotecan & $4(4.3)$ & $15(2.6)$ & & $4(4.9)$ & $5(1.2)$ & & $4(5.8)$ & $4(1.7)$ & \\
\hline CAV & $6(6.5)$ & $62(10.7)$ & & $6(7.4)$ & $42(10.4)$ & & $6(8.7)$ & $28(11.6)$ & \\
\hline 3rd line Chemotherapy, n (\%) & $4(4.3)$ & $26(4.5)$ & & $4(4.9)$ & $18(4.5)$ & & $4(5.8)$ & $9(3.7)$ & \\
\hline
\end{tabular}

$40 \%$ had PS2 or more, and almost $30 \%$ had moderate or severe co-morbidities. Most patients received carboplatin-based chemotherapy: $97 \%$ in the 4c group and $99 \%$ in the $>4 \mathrm{c}$. In that latter group, $84 \%$ completed 6 cycles, reaching an average of 5.8 cycles. Again, response rates were similar in both groups.
Whereas PCI rates were less than $40 \%$ in both groups, the rates of radiotherapy to the lung were higher in the patients treated with a longer regimen $(25 \%$ in $4 \mathrm{c}$ versus $39 \%$ in $>4 c$ ). The intent of thoracic radiotherapy was in all cases palliative. There were no differences in second line treatment rates, and the proportion of platinum

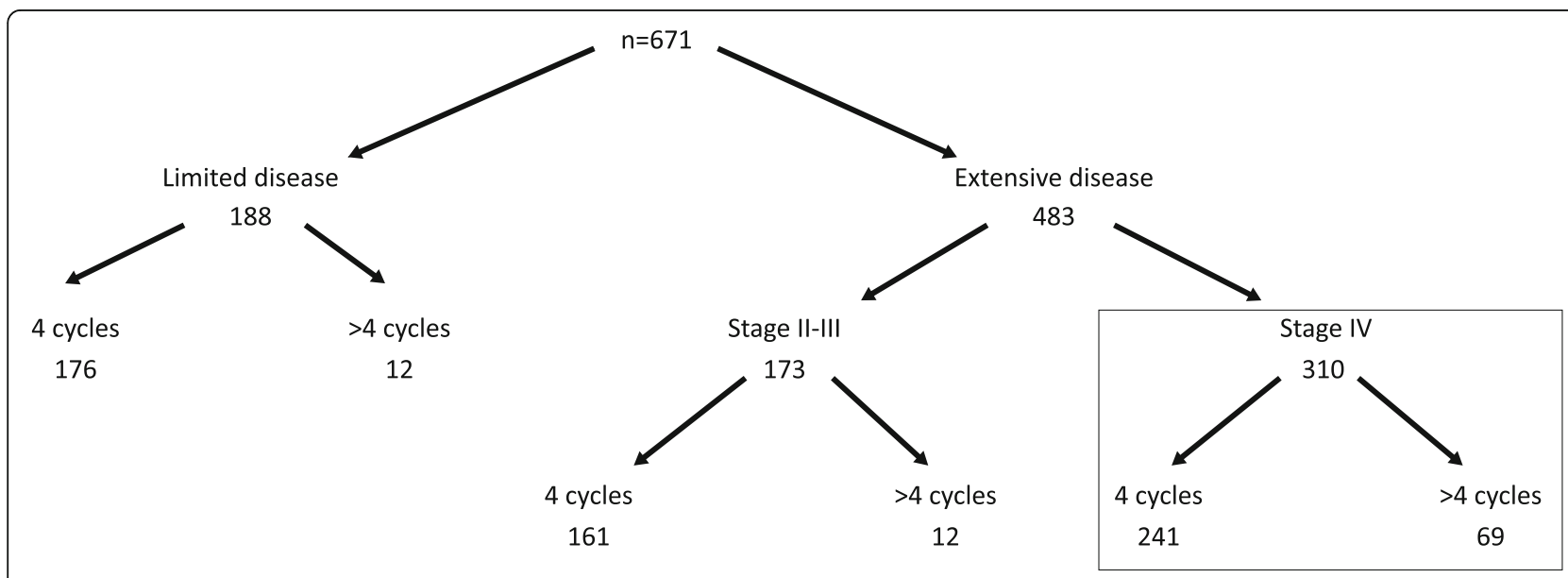

Fig. 1 Patient flow diagram 
re-challenge was $12 \%$ in the $4 \mathrm{c}$ group versus $9 \%$ in the $>4 \mathrm{c}$.

\section{Treatment outcomes}

The similar rate of platinum re-challenge was concordant with the clinical outcomes measured: there were no significant differences in duration of response (DoR), progression free survival (PFS) or overall survival (OS) in patients with stage IV disease.

DoR curves (time from the last cycle administration to disease recurrence) for patients that completed first line PE treatment are shown in Fig. 2, with a median DoR of 5 months in both groups. The HR for $>4 \mathrm{c}$ was $1.22(95 \%$ CI $0.93-1.61 ; p=0.104)$, and the 6 month DoR was $48 \%$ for the $4 \mathrm{c}$ group versus $33 \%$ for the $>4 \mathrm{c}$.

PFS curves (see Fig. 3) show a median PFS of 8 (4c) versus 9 months $(>4 \mathrm{c})$, with an $\mathrm{HR}$ for $>4 \mathrm{c}$ of 0.86 (95\% CI $0.66-1.13 ; p=0.225$ ). Respectively, the 6-month PFS was $86 \%$ versus $96 \%$, and the 1 year PFS $20 \%$ versus $23 \%$.

The median OS (see Fig. 4) was 11 months for the patients in the shorter treatment and 12 months for the longer schedule, with an HR for $>4 \mathrm{c}$ of $0.86(95 \% \mathrm{CI}$
$0.66-1.14 ; p=0.28)$. The one-year OS was 35 and $46 \%$ respectively.

\section{Discussion}

To our knowledge, this is the largest study analysing the effect of extending platinum doublet treatment beyond 4 cycles in patients with stage IV SCLC disease. Our selected real-life patients with stage IV SCLC did not improve disease control or survival by extending first line platinum and etoposide combination treatment beyond 4 cycles.

The retrospective nature of the study was an important limitation, restricting accurate quantification of the timing of the treatment length decision - at presentation or after 3-4 cycles -, and treatment toleration. The latter was related to inter-consultant differences in patient assessment as well as changes in standard toxicity chemotherapy nurse documentation during the study time. Noticeably, there was a low proportion of patients that went on to complete more than 4 cycles of chemotherapy: only 93 (14\%) of the 671 initial population and $69(22 \%)$ of the 310 patients with stage IV. These numbers suggested high patient selection, a bias that would favour the longer treatment group. Nevertheless,

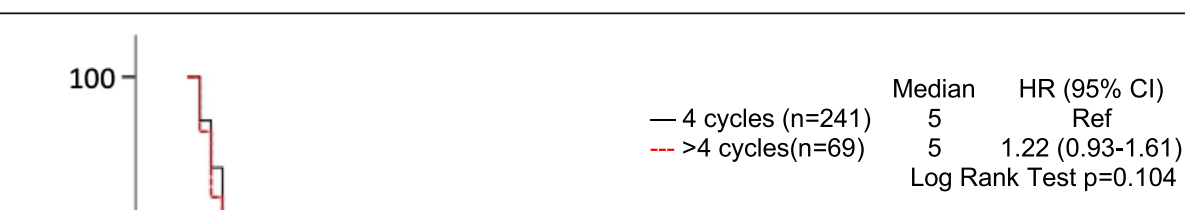

Months (from last cyle date)

No. at risk

$\begin{array}{lcccccccccc}4 \text { cycles } & 241 & 116 & 23 & 13 & 7 & 4 & 3 & 1 & 1 & 1 \\ >4 \text { cycles } & 69 & 23 & 6 & 2 & 0 & 0 & 0 & 0 & 0 & 0\end{array}$

Fig. 2 Kaplan Meyer curve of time from last chemotherapy cycle to date of progression or death (DoR; Duration of Response) 

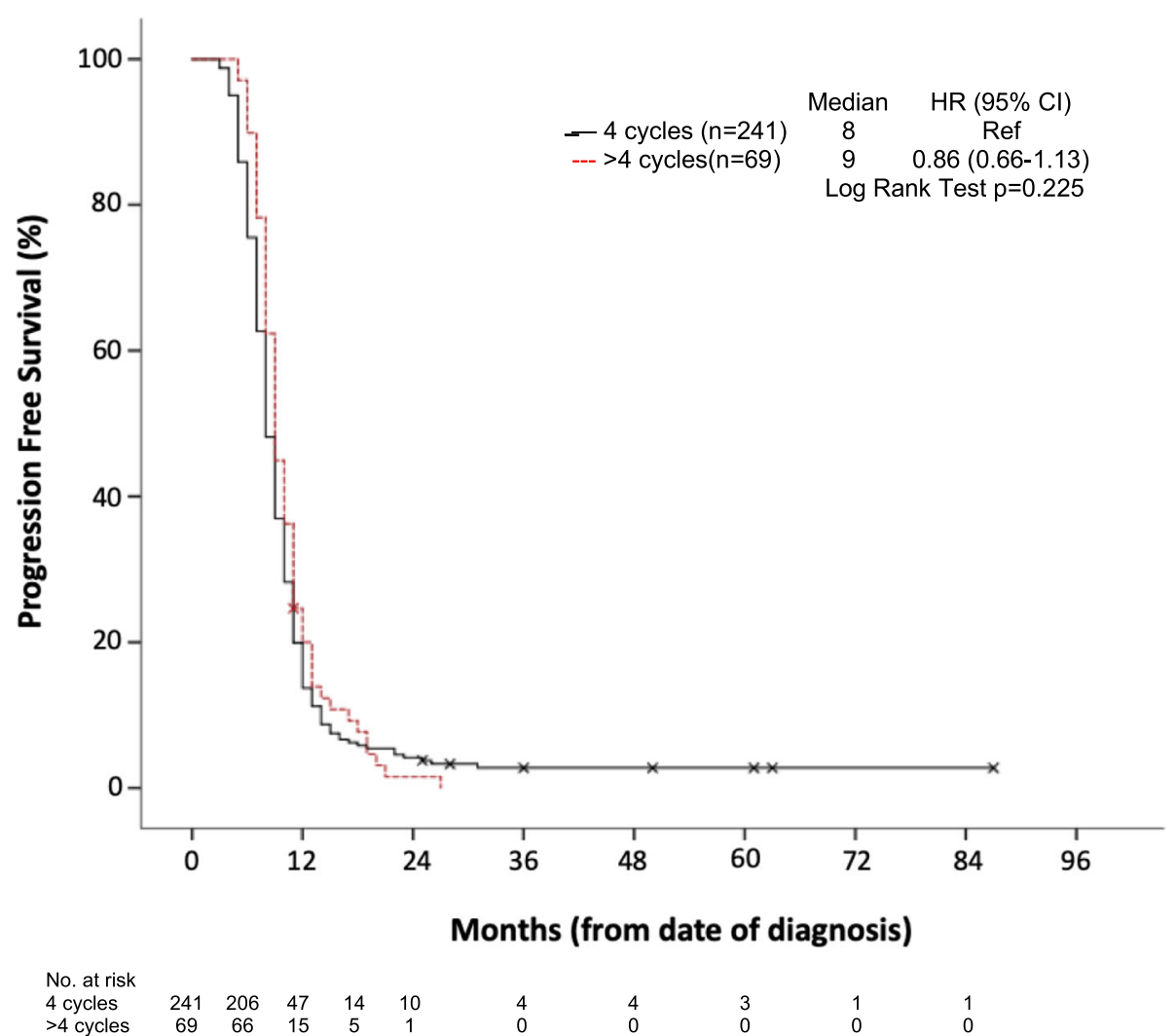

Fig. 3 Kaplan Meyer curve of time from diagnosis to date of disease progression or death (PFS; Progression Free Survival)

radiological response (the one measurable selection criteria available) was similar in patients with stage IV regardless of treatment length. This may have been due to (a) inaccurate patient selection on radiological assessment of response, (b) a fundamental reliance on treatment toleration, or (c) a decision of treatment length intent at presentation based on non-recorded criteria such as clinical relevance of metastatic burden.

The latter possibility may have been evident when exploring differences in subsequent treatment between the groups. $39 \%(n=27)$ of patients in the $>4$ c group went on to have palliative radiation to the lung, whereas only $25 \%(n=61)$ of the $4 c$ group received the same treatment. The clinical benefit in extensive disease is limited [10], but may suggest a lower clinical relevance of the metastatic burden in this particular subpopulation. In spite of this bias that would favour the $>4 \mathrm{c}$ population no differences in clinical outcomes were observed.

Another potential bias inherent to retrospective studies is a suspected variability in the timing of patient review and investigations during follow up, influencing the diagnosis of recurrence. Still, there is no reason to expect differences in follow up related to the length of the first line treatment, hence we assumed equal distribution of this bias in both treatment groups.

As expected, our PFS and OS values were better than those previously reported [4]. Patients that received 3 or less treatment cycles were not included and therefore their outcome did not burden the clinical measures of the populations studied here.

Caution is required when extrapolating our results to patients with early stage disease, as there were only small numbers in our long treatment cohort, and they were excluded from clinical outcome calculations (see Fig. 1). However, in view of the observed lack of benefit of a longer treatment in extensive disease, and the lack of prospective evidence of benefit in limited stage [17], it would be reasonable to question the benefit of treating beyond 4 cycles in patients with limited disease undergoing sequential chemoradiotherapy.

\section{Conclusion}

Our real-life data in stage IV disease does not support treatment beyond 4 cycles of PE combination. That is consistent with the lack of benefit seen in randomised prospective studies comparing 4 cycles with 6 cycles of either a hybrid regimen [16] or cisplatin and etoposide 


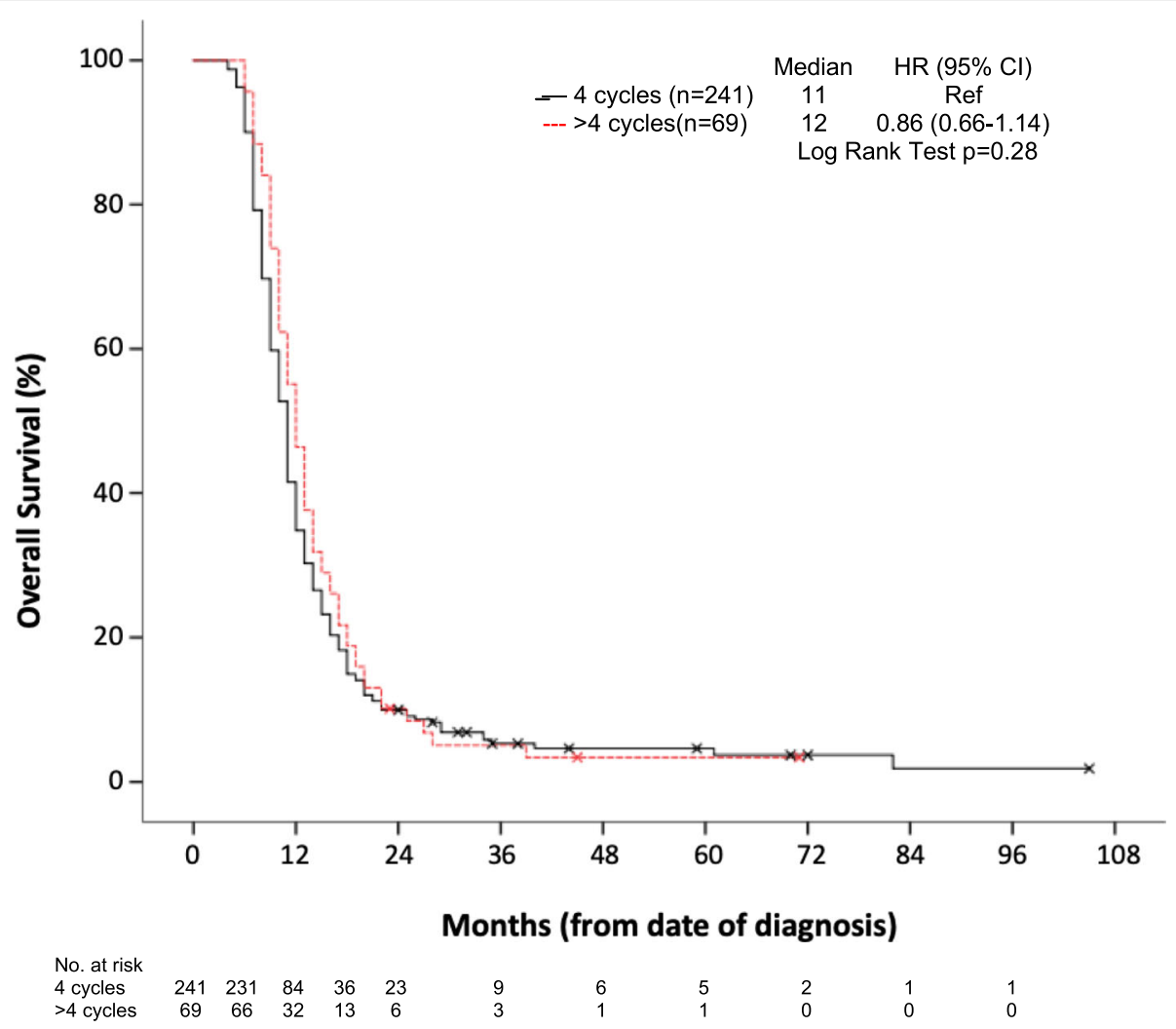

Fig. 4 Kaplan Meyer curve of time from diagnosis to death (OS; Overall Survival)

[17]. Limiting treatment to 4 cycles may contribute to avoid unnecessary hospital visits and toxicity, optimise treatment cost-effectiveness and perhaps increase the focus on recruitment into clinical trials exploring novel strategies [26] with the potential of improving survival outcomes.

\section{Abbreviations}

$>$ 4c: More than four cycles; 4c: Four cycles; CAV: Vincristine, Doxorubicin and Cyclophosphamide; Cl: Confidence Interval; DoR: Duration of Response; HR: Hazard Ratio; OS: Overall Survival; PCl: Prophylactic Cranial Irradiation; PE: Platinum and Etoposide; PFS: Progression-Free Survival; SCLC: Small Cell Lung Cancer

\section{Acknowledgements}

We are deeply grateful to the advice of Dr. Olusola Faluyi and the entire Clinical Excellence Team at The Clatterbridge Cancer Centre for their prospective data collection efforts.

\section{Authors' contributions}

The study was planned by CE. MS collected all the retrospective clinical data and checked the accuracy of prospective data collection. CE and HW performed two different independent in-depth data analysis at different time points. CE wrote the manuscript. All authors have read and approved the manuscript.

\section{Funding}

No funding was required for this particular study

\section{Availability of data and materials}

The datasets used and analysed during the current study are available from the corresponding author on reasonable request.
Ethics approval and consent to participate

Study approval was obtained by the Audit Committee at The Clatterbridge Cancer Centre before access to patient data collection was granted.

\section{Consent for publication}

This was not deemed necessary by the local audit committee.

\section{Competing interests}

The authors declare that they have no competing interests.

Received: 14 May 2019 Accepted: 23 September 2019

Published online: 01 November 2019

\section{References}

1. Hendifar AE, Marchevsky AM, Tuli R. Neuroendocrine tumors of the lung: current challenges and advances in the diagnosis and Management of Well-Differentiated Disease. J Thorac Oncol. 2017;12(3):425-36.

2. Riaz SP, Luchtenborg M, Coupland VH, Spicer J, Peake MD, Moller H. Trends in incidence of small cell lung cancer and all lung cancer. Lung Cancer. 2012;75(3):280-4

3. Khakwani A, Rich AL, Tata LJ, Powell HA, Stanley RA, Baldwin DR, et al. Small-cell lung cancer in England: trends in survival and chemotherapy using the National Lung Cancer Audit. PLoS One. 2014;9(2):e89426.

4. Foster NR, Qi Y, Shi Q, Krook JE, Kugler JW, Jett JR, et al. Tumor response and progression-free survival as potential surrogate endpoints for overall survival in extensive stage small-cell lung cancer: findings on the basis of north central Cancer treatment group trials. Cancer. 2011;117(6):1262-71.

5. Fruh M, De Ruysscher D, Popat S, Crino L, Peters S, Felip E. Small-cell lung cancer (SCLC): ESMO Clinical Practice Guidelines for diagnosis, treatment and follow-up. Ann Oncol. 2013;24(Suppl 6):vi99-105.

6. Kalemkerian GP, Akerley W, Bogner P, Borghaei H, Chow LQ, Downey RJ, et al. Small cell lung cancer. J Natl Compr Cancer Netw. 2013;11(1):78-98. 
7. Slotman B, Faivre-Finn C, Kramer G, Rankin E, Snee M, Hatton M, et al. Prophylactic cranial irradiation in extensive small-cell lung cancer. N Engl J Med. 2007;357(7):664-72.

8. Pignon JP, Arriagada R, Ihde DC, Johnson DH, Perry MC, Souhami RL, et al. A meta-analysis of thoracic radiotherapy for small-cell lung cancer. $N$ Engl J Med. 1992:327(23):1618-24.

9. Warde P, Payne D. Does thoracic irradiation improve survival and local control in limited-stage small-cell carcinoma of the lung? A meta-analysis. J Clin Oncol. 1992;10(6):890-5.

10. Slotman BJ, van Tinteren H, Praag JO, Knegjens JL, El Sharouni SY, Hatton M, et al. Use of thoracic radiotherapy for extensive stage small-cell lung cancer: a phase 3 randomised controlled trial. Lancet. 2015;385(9962):36-42.

11. Crivellari G, Monfardini S, Stragliotto S, Marino D, Aversa SM. Increasing chemotherapy in small-cell lung cancer: from dose intensity and density to megadoses. Oncologist. 2007:12(1):79-89.

12. Schiller JH, Adak S, Cella D, DeVore RF 3rd, Johnson DH. Topotecan versus observation after cisplatin plus etoposide in extensive-stage small-cell lung cancer: E7593--a phase III trial of the eastern cooperative oncology group. J Clin Oncol. 2001;19(8):2114-22.

13. Hanna NH, Sandier AB, Loehrer PJ Sr, Ansari R, Jung SH, Lane K, et al. Maintenance daily oral etoposide versus no further therapy following induction chemotherapy with etoposide plus ifosfamide plus cisplatin in extensive small-cell lung cancer: a Hoosier oncology group randomized study. Ann Oncol. 2002;13(1):95-102.

14. Zhou H, Zeng C, Wei Y, Zhou J, Yao W. Duration of chemotherapy for small cell lung cancer: a meta-analysis. PLoS One. 2013:8(8):e73805.

15. Bozcuk H, Artac M, Ozdogan M, Savas B. Does maintenance/consolidation chemotherapy have a role in the management of small cell lung cancer (SCLC)? A metaanalysis of the published controlled trials. Cancer. 2005; 104(12):2650-7.

16. Roth BJ, Johnson DH, Einhorn LH, Schacter LP, Cherng NC, Cohen HJ, et al. Randomized study of cyclophosphamide, doxorubicin, and vincristine versus etoposide and cisplatin versus alternation of these two regimens in extensive small-cell lung cancer: a phase III trial of the southeastern Cancer study group. J Clin Oncol. 1992;10(2):282-91.

17. Veslemes M, Polyzos A, Latsi P, Dimitroulis J, Stamatiadis D, Dardoufas C, et al. Optimal duration of chemotherapy in small cell lung cancer: a randomized study of 4 versus 6 cycles of cisplatin-etoposide. J Chemother. 1998;10(2):136-40.

18. Crona DJ, Faso A, Nishijima TF, McGraw KA, Galsky MD, Milowsky MI. A systematic review of strategies to prevent Cisplatin-induced nephrotoxicity. Oncologist. 2017;22(5):609-19.

19. Rossi A, Di Maio M, Chiodini P, Rudd RM, Okamoto H, Skarlos DV, et al. Carboplatin- or cisplatin-based chemotherapy in first-line treatment of small-cell lung cancer: the COCIS meta-analysis of individual patient data. J Clin Oncol. 2012;30(14):1692-8.

20. Morabito A, Daniele G, Costanzo R, Favaretto AG, Filipazzi V, Rossi A, et al. A multicenter, randomized, phase 3 trial comparing fixed dose versus toxicityadjusted dose of cisplatin + etoposide in extensive small-cell lung cancer (SCLC) patients: the small-cell-lung cancer toxicity adjusted dosing (STAD-1) trial. Lung Cancer. 2017;108:15-21.

21. Altan M, Chiang AC. Management of Small Cell Lung Cancer: Progress and updates. Cancer J. 2015;21(5):425-33.

22. Califano R, Abidin AZ, Peck R, Faivre-Finn C, Lorigan P. Management of small cell lung cancer: recent developments for optimal care. Drugs. 2012; 72(4):471-90.

23. Puglisi M, Dolly S, Faria A, Myerson JS, Popat S, O'Brien ME. Treatment options for small cell lung cancer - do we have more choice? Br J Cancer 2010;102(4):629-38.

24. Alvarado-Luna G, Morales-Espinosa D. Treatment for small cell lung cancer, where are we now?-a review. Transl Lung Cancer Res. 2016;5(1):26-38,

25. Horn L, Mansfield AS, Szczesna A, Havel L, Krzakowski M, Hochmair MJ, et al. First-line Atezolizumab plus chemotherapy in extensive-stage small-cell lung Cancer. N Engl J Med. 2018;379:2220-9.

26. Romanidou O, Imbimbo M, Mountzios G, Abidin A, Morgillo F, Califano R. Therapies in the pipeline for small-cell lung cancer. Br Med Bull. 2016;119(1): $37-48$.

\section{Publisher's Note}

Springer Nature remains neutral with regard to jurisdictional claims in published maps and institutional affiliations.

Ready to submit your research? Choose BMC and benefit from:

- fast, convenient online submission

- thorough peer review by experienced researchers in your field

- rapid publication on acceptance

- support for research data, including large and complex data types

- gold Open Access which fosters wider collaboration and increased citations

- maximum visibility for your research: over $100 \mathrm{M}$ website views per year

At BMC, research is always in progress.

Learn more biomedcentral.com/submissions 